\title{
Natural Products as a Source of Environmentally Friendly Corrosion Inhibitors: The Case of Gum Exudate from Acacia seyal var. seyal
}

\author{
J. Buchweishaija, ${ }^{*}$ G.S. Mhinzi \\ Chemistry Department, University of Dar es Salaam, P.O. Box 35061, Dar es Salaam, Tanzânia
}

Received 6 June 2007; accepted 26 September 2007

\begin{abstract}
The inhibitive effect of the gum exudate from Acacia seyal var. seyal on the corrosion of mild steel in drinking water was investigated using potentiodynamic polarization and electrochemical impedance spectroscopy (EIS) techniques. The results obtained show that gum exudates could serve as effective inhibitors for the corrosion of steel in drinking water network. The percentage inhibition increases with increasing the concentration of the gum at $30{ }^{\circ} \mathrm{C}$. The percentage inhibitor efficiency above $95 \%$ was attained at gum concentration $\geq 400 \mathrm{ppm}$. The corrosion rates of steel and inhibition efficiencies of the gum exudates obtained from impedance and polarization measurements were in good agreement. Potentiodynamic polarization studies clearly reveal that the gum behaves predominantly as an anodic inhibitor. The study also shows that the inhibition efficiency was insignificantly affected by the temperature rise of the medium.
\end{abstract}

Keywords: corrosion, inhibitor, acacia seyal, gum exudates, mild steel.

\section{Introduction}

Corrosion of metals in wet environments is a serious problem in many industries and civil services such as water distribution systems. Potable water distribution systems are usually durable in average water compositions but their integrity can be compromised when exposed to water compositions containing aggressive chemicals such as chloride, sulfate and the like. Corrosion reduces the service life of the system and changes the quality of water conveyed through these distribution systems [1-4].

\footnotetext{
* Corresponding author. E-mail address: buchwe@chem.udsm.ac.tz
} 
A number of options exist for mitigating corrosion of potable water distribution systems and use of corrosion inhibitors is among the best options. However, the choice of a proper corrosion inhibitor to be applied in these systems is limited due to the potable criteria of water. Inhibitors to be used in potable water systems ought to be safe to human and friendly to the environment. Currently, there is public criticism of synthesized chemicals that are used in water systems and hence, the search for inhibitors derived from natural products seems to be an interesting option [5-7]. Nowadays, natural products are viewed as incredibly rich sources of naturally synthesized chemicals for use in most applications. Some of the advantages that natural chemicals have over other types of chemicals include being environmentally acceptable and is a readily available resource. Some investigations have been reported using such economic natural resources [8].

In our continued investigation of natural corrosion inhibitor materials, Acacia gum exudates are introduced for the first time as a safe and cheap corrosion inhibitor for commercial grade metals used in potable water systems. Acacia gum exudates are obtained from the stems and branches of sub-Saharan leguminosae trees, which grow extensively in central parts of Tanzania. Acacia gum, particularly that from Acacia senegal, is a permitted food additive used in the preparation of diary, confectionary and bakery products [9-11] and is a complex natural polysaccharides. Structurally, these gum exudates consist of surfaceactive units such as amino $\left(-\mathrm{NH}_{2}\right)$, hydroxyl $(-\mathrm{OH})$ and carboxyl $(-\mathrm{COOH})$, which suggest them to be electrochemically active and they can therefore interact with metallic surfaces through these units and inhibit corrosion [12,13].

This paper presents a study of the gum exudates from Acacia seyal var. seyal as an inhibitor for mild steel corrosion in drinking water systems and discusses the effect of temperature on its inhibition mechanism.

\section{Experimental procedure}

The specimens used for constructing the working electrodes were machined from the parent metallic pipe material used for domestic piping and plumbing in Dar es Salaam, Tanzania. This steel had the following chemical composition (wt \%): $0.07 \mathrm{C}, 0.25 \mathrm{Si}, 1.30 \mathrm{Mn}, 0.02 \mathrm{Cr}, 0.01 \mathrm{Ni}, 0.10 \mathrm{Mo}, 0.039 \mathrm{~V}$ and balance Fe. Cylindrical electrodes mounted in teflon tubes served as working electrodes. The exposed area of the metallic surface was $0.07 \mathrm{~cm}^{2}$. Prior to carrying out the corrosion tests, the metal specimens were mechanically ground successively with 400 to 4000 grit silicon carbide papers followed by polishing with diamond paste (9 to $1.0 \mu \mathrm{m}$ ) to achieve mirror finish surfaces. The specimens were then ultrasonically degreased in acetone, washed thoroughly with distilled water, dried with a jet of hot air and immediately introduced into the corrosive solution.

The tests were carried out in a $100 \mathrm{~mL}$ three electrodes thermostatically controlled cell made of Pyrex glass with a Rotating Disk Electrode (RDE) assembly. The experimental set up has been described in detail elsewhere [14]. The corrosive medium was chlorinated drinking water collected from Upper Ruvu water work, Coast region, Tanzania. The corrosion inhibitor used was one 
of the gum exudates collected from Singida in Tanzania and this was Acacia seyal var. seyal. The performance of the gum exudates from that species as a corrosion inhibitor was monitored in the concentration range from 0 to $1000 \mathrm{ppm}$ $(\mathrm{v} / \mathrm{v})$ at $30{ }^{\circ} \mathrm{C}$. For each experiment fresh water solutions as well as freshly polished metallic samples were used. The study presented here was carried out at a single rotation speed of $3000 \mathrm{rpm}$ that corresponds to a peripheral velocity of $7.1 \mathrm{~m} / \mathrm{s}$, a shear stress of $1.6 \mathrm{~Pa}$ and a Reynolds number of 886 . The effect of temperature on the performance of the optimal concentration of gum exudates was also studied at 50 and $80{ }^{\circ} \mathrm{C}$.

Two electrochemical techniques were employed to observe the corrosion processes for both inhibited and uninhibited media. These were electrochemical impedance spectroscopy and potentiodynamic polarization techniques. The former was carried out by a computer controlled AUTOLAB Frequency Response Analyzer (FRA) in the frequency range of $10 \mathrm{kHz}$ to $10 \mathrm{mHz}$ at a sweeping rate of 10 points per decade, logarithmic division. Measurements were taken at various time intervals ranging from 2 to 12 hours at open circuit potential. Potentiodynamic polarization measurements were performed using a computer-controlled potentiostat, AUTOLAB PGSTAT20 from ECO CHEMIE, Netherlands. Cathodic and anaodic polarization curves were each recorded on separate electrode by sweeping at a rate of $1 \mathrm{mV} / \mathrm{s}$ over a range of $100 \mathrm{mV}$ vs. $\mathrm{Ag} / \mathrm{AgCl}$ from the open circuit potential. Platinum sheet was used as a counter electrode and a saturated $\mathrm{Ag} / \mathrm{AgCl}$ as reference electrode. All polarization curves were taken at the end of the exposure time to avoid alteration of the surface.

\section{Results and discussion}

It is well established that polarization curves can help to understand how a certain corrosion inhibitor works. Inhibitors can modify the anodic process, the cathodic process or both leading to a decreased rate of the global corrosion process. Fig. 1 shows typical polarization curves for mild steel carried in aerated potable water in the absence and presence of varied concentrations of exudates of Acacia seyal var. seyal.

In the figure, two important trends are evident. Firstly, that the gum exudate is found to block the electrochemical processes taking place on the steel undergoing corrosion in water. It reduces both the rate of cathodic and anodic reactions by reducing the current densities on both sides of the polarization curves in the potential region studied and hence reduces the corrosion rate. Secondly, it shifts the open corrosion potentials towards less negative values with reference to the blank. These factors suggest that the A. seyal var. seyal inhibitor acts as anodic type corrosion inhibitor $[12,13]$. 


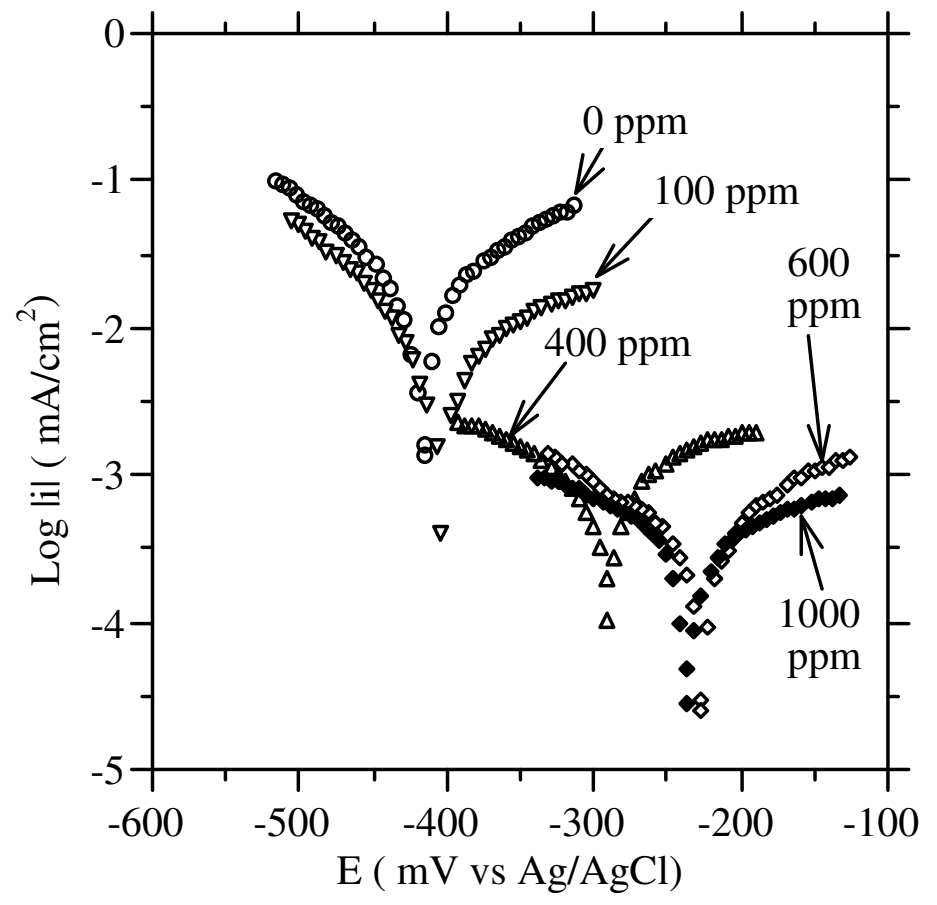

Figure 1. Polarization curves for mild steel in potable water containing different concentrations of Acacia seyal var. seyal gum exudates; $\mathrm{T}=30^{\circ} \mathrm{C}$.

The data obtained from polarization curves by Tafel extrapolations are presented in Table 1 . These include corrosion potential $\left(\mathrm{E}_{\text {corr. }}\right)$, corrosion current density $\left(\mathrm{i}_{\text {corr. }}\right)$, and calculated corrosion rates in mils per year (mpy) at varied exudates concentrations. It can be seen from Table 1 that the corrosion rates decrease tremendously as the inhibitor concentrations increases. The corrosion potential, $\mathrm{E}_{\text {corr }}$, becomes less negative as the concentration increases. However, there is a slight variation in both anodic and cathodic Tafel slopes indicating that the inhibiting action takes place by simple blocking of the available cathodic and anodic sites on the metal surface [8].

The Table also gives the percentage Inhibitor Efficiency (\% IE) for the gum exudate from Acacia seyal var. seyal applied. The \% IE was calculated using the relation

$$
\% \mathrm{IE}=\left(1-\left(\mathrm{i}_{\text {corr.,i }} / \mathrm{i}_{\text {corr, } \mathrm{w}}\right)\right) \times 100
$$

where $i_{\text {corr., }}$ and $i_{\text {corr.,w }}$ are the corrosion rates with and without inhibitor, respectively. The corrosion rate values for mild steel in potable water containing various concentrations of inhibitor are smaller than the values obtained by potable water alone (Table 1). The calculated corrosion rate of mild steel in the uninhibited potable water was $2.911 \mathrm{mpy}$ and this value decreased to about 0.046 mpy with $600 \mathrm{ppm}$ of the inhibitor. This corresponds to the corrosion inhibition efficiency of about $98 \%$. 
Table 1. Electrochemical parameters for the corrosion of mild steel exposed in potable water with different concentrations of gum exudates of $A$. seyal var. seyal and the corresponding corrosion inhibition efficiency; $\mathrm{T}=30^{\circ} \mathrm{C}$.

\begin{tabular}{|c|c|c|c|c|c|c|}
\hline $\begin{array}{c}\mathrm{C}_{\mathrm{inh}} \\
(\mathrm{ppm})\end{array}$ & $\begin{array}{l}\quad \mathrm{E}_{\mathrm{corr}} \\
(\mathrm{mVvs.Ag} \\
\mathrm{Cl})\end{array}$ & $\begin{array}{c}\mathrm{i}_{\text {corr }} \\
\left(\begin{array}{c}\mu \mathrm{A} / \mathrm{cm} \\
2\end{array}\right)\end{array}$ & $\begin{array}{c}R \\
\text { (mpy) }\end{array}$ & $\begin{array}{c}b_{\mathrm{c}} \\
(\mathrm{mV} / \mathrm{dec} \\
)\end{array}$ & $\begin{array}{c}b_{\mathrm{a}} \\
(\mathrm{mV} / \mathrm{de} \\
\mathrm{c})\end{array}$ & $\begin{array}{l}\mathrm{IE} \\
(\%)\end{array}$ \\
\hline Blank & -415 & 6.300 & 2.911 & -50 & 48 & - \\
\hline 100 & -403 & 1.660 & 0.767 & -35 & 35 & 73.6 \\
\hline 400 & -293 & 0.260 & 0.120 & -40 & 50 & 95.8 \\
\hline 600 & -229 & 0.070 & 0.046 & -32 & 45 & 98.4 \\
\hline 1000 & -234 & 0.095 & 0.044 & -35 & 39 & 98.5 \\
\hline
\end{tabular}

The inhibition process of the gum exudates was also studied by electrochemical impedance spectroscopy technique. Impedance measurements in the Nyquist format for mild steel exposed for 12 hours in the aerated potable water containing different concentrations of the gum exudates from Acacia seyal var. seyal are shown in Fig. 2. It is seen from this figure that the presence of the gum in the drinking water leads to changes of the impedance diagram in both shape and size. It is clear from this figure that the impedance diagrams are not perfect semicircles reported to be attributed to the frequency dispersion [15]. The size of the capacitive arc increased with increase in inhibitor concentrations up to 600 ppm and remained almost unchanged with further increase of the concentration to $1000 \mathrm{ppm}$. This suggests that, $600 \mathrm{ppm}$ could be considered as the optimum inhibitor concentration forming the optimum protective film on the substrate surface against the charge transfer.

The impedance spectra for different Nyquist plots were analyzed using a Complex Nonlinear Least Squares (CNLS) fitting program, EQUIVCRT and the equivalent circuit model and relevant relations used are described elsewhere [14]. The values of elements fitted the model, that is, charge transfer resistances $\left(\mathrm{R}_{\mathrm{ct}}\right)$ and that of double layer capacitances $\left(\mathrm{C}_{\mathrm{dl}}\right)$ calculated are listed in Table 2.

The table also includes the open circuit potential, calculated corrosion rates and percentage inhibitor efficiency (\% IE). Since, the corrosion rate is inversely proportional to the charge transfer; \% IE was calculated by use of the relation given above. It is seen from this table that as inhibitor concentration increases, the $\mathrm{R}_{\mathrm{ct}}$ values increase while the double-layer capacitance decreases. This indicates that, gum exudate from Acacia seyal var. seyal is corrosion inhibitive in nature. The decrease in the $\mathrm{C}_{\mathrm{dl}}$ values in the presence of the gum shows that gum adsorbs on the metal surface and forms a film that reduces the metal surface area undergoing corrosion. It has been reported that the adsorption process on the metal surface is characterized by a decrease in $\mathrm{C}_{\mathrm{dl}}$ [8]. The inhibition efficiencies obtained by impedance studies are in agreement with those obtained employing potentiodynamic polarization technique. 


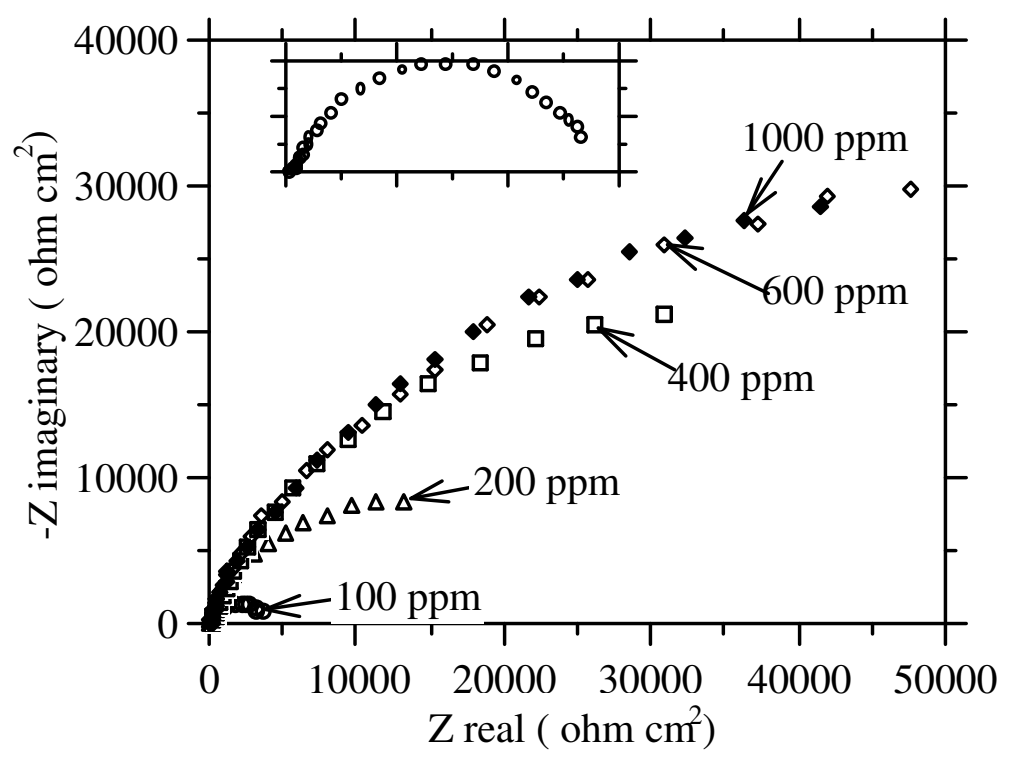

Figure 2. Impedance spectra in Nyquist format for mild steel in potable water with different concentrations of Acacia seyal var. seyal. The inset shows the Nyquist plot for the blank; $\mathrm{T}=30{ }^{\circ} \mathrm{C}$.

Table 2. Electrochemical parameters for the corrosion of mild steel exposed in potable water with different concentrations of gum exudates of $A$. seyal var. seyal and the corresponding corrosion inhibition efficiency; $\mathrm{T}=30^{\circ} \mathrm{C}$.

\begin{tabular}{|c|c|c|c|c|c|}
\hline $\begin{array}{l}\mathrm{C}_{\mathrm{inh}} \\
(\mathrm{ppm})\end{array}$ & $\begin{array}{c}\mathrm{E}_{\text {ocp }} \\
\text { (mV vs. } \\
\mathrm{Ag} / \mathrm{AgCl})\end{array}$ & $\begin{array}{c}\mathrm{R}_{\mathrm{ct}} \\
\left(\Omega \mathrm{cm}^{2}\right)\end{array}$ & $\begin{array}{c}\mathrm{C}_{\mathrm{dl}} \\
\mu \mathrm{F} / \mathrm{cm}^{2}\end{array}$ & (mpy) & $\mathrm{IE}$ \\
\hline Blank & -450 & 1,091 & 1,075 & 4.708 & - \\
\hline 100 & -407 & 3,757 & 810 & 0.970 & 70.9 \\
\hline 200 & -338 & 20,949 & 311 & 0.152 & 94.8 \\
\hline 400 & -295 & 58,032 & 128 & 0.078 & 98.1 \\
\hline 600 & -236 & 71,582 & 64 & 0.055 & 98.5 \\
\hline 1,000 & -246 & 71,010 & 58 & 0.055 & 98.5 \\
\hline
\end{tabular}

In order to further understand on the gum exudate from A. seyal var. seyal corrosion inhibition properties, the influence of temperatures on its performance was also investigated. Temperatures up to $80{ }^{\circ} \mathrm{C}$ were studied, using an optimal concentration of the gum $(600 \mathrm{ppm})$ under dynamic condition $(3000 \mathrm{rpm})$. Fig. 3(A) and (B) show potentiodynamic polarization plots for steel in drinking water with and without inhibitor at 30,50 and $80{ }^{\circ} \mathrm{C}$, respectively. The measurements were performed after 10 hours of immersion in the media.

The inhibitor efficiencies calculated from these results are shown in Table 3 together with the extrapolated corrosion current densities and corrosion potentials. The table shows that the percentage inhibitor efficiencies are nearly constant in the temperature range studied and hence change in temperature was found to have insignificant influence on the performance of the gum. This shows that the gum from Acacia seyal var. seyal is temperature insensitive. 

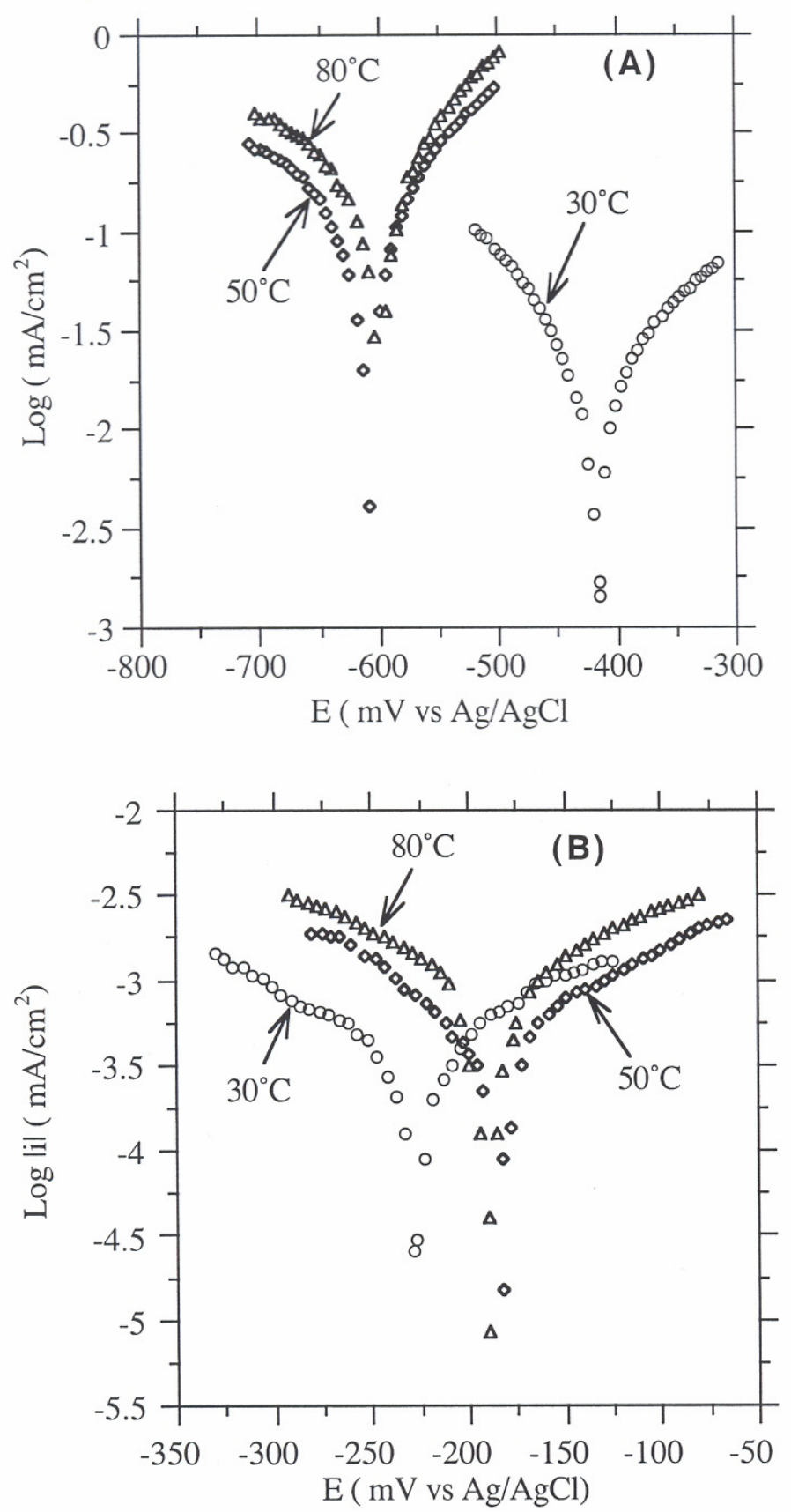

Figures 3. Temperature effects on mild steel in potable water: (A) uninhibited; (B) inhibited.

It has been reported by a number of researchers that the logarithm of corrosion rate is a linear function with the reciprocal of the absolute temperature (Arrhenius equation):

$$
i_{\text {corr }}=K \exp \left(\frac{-E_{a}}{R T}\right)
$$

where $E_{a}$ is the apparent activation energy and $K$ is a constant. The activation energies for the mild steel dissolution process in the absence and presence of 600 
ppm inhibitor were evaluated from the linear square fit of $\ln (i)_{\text {corr. }}$ vs $1000 / \mathrm{T}$ as shown in Fig. 4. The plots have slopes of -4.1155 and -2.4516 for without and with inhibitor, respectively. Similarly, the intercepts $\left(\ln \left(i_{\text {corr }}\right)\right)$ are 15.362 and 5.450 for without and with inhibitor, respectively. Because of the reduced parameters when inhibitor is used, corrosion current which reflects the rate of corrosion, increases less rapidly with increasing temperature for situations with inhibitor than without in the temperature range used in these experiments. This indicates that the temperature does not affect the adsorption of the gum.

Table 3. The influence of temperature on the electrochemical parameters of mild steel in potable waters with $600 \mathrm{ppm}$ of gum exudates of $A$. seyal var. seyal.

\begin{tabular}{|c|c|c|c|c|c|}
\hline $\begin{array}{c}\text { Temp. } \\
\left({ }^{\circ} \mathrm{C}\right)\end{array}$ & \multicolumn{2}{|c|}{ Blank/mild steel } & \multicolumn{3}{c|}{$\begin{array}{c}\text { Acacia gum from seyal var. seyal } \\
\text { on mild steel }(600 \mathrm{ppm})\end{array}$} \\
\hline & $\begin{array}{c}\mathrm{E}_{\mathrm{corr}} \\
(\mathrm{mV})\end{array}$ & $\begin{array}{c}\mathrm{i}_{\text {corr }} \\
\left(\mu \mathrm{A} / \mathrm{cm}^{2}\right)\end{array}$ & $\begin{array}{c}\mathrm{E}_{\text {corr }} \\
(\mathrm{mV})\end{array}$ & $\begin{array}{c}\mathrm{i}_{\text {corr }} \\
\left(\mu \mathrm{A} / \mathrm{cm}^{2}\right)\end{array}$ & $\begin{array}{c}\mathrm{IE} \\
(\%)\end{array}$ \\
\hline 30 & -415 & 6.30 & -229 & 0.07 & 98.4 \\
50 & -614 & 19.98 & -181 & 0.12 & 97.1 \\
80 & -602 & 44.65 & -188 & 0.24 & 96.8 \\
\hline
\end{tabular}

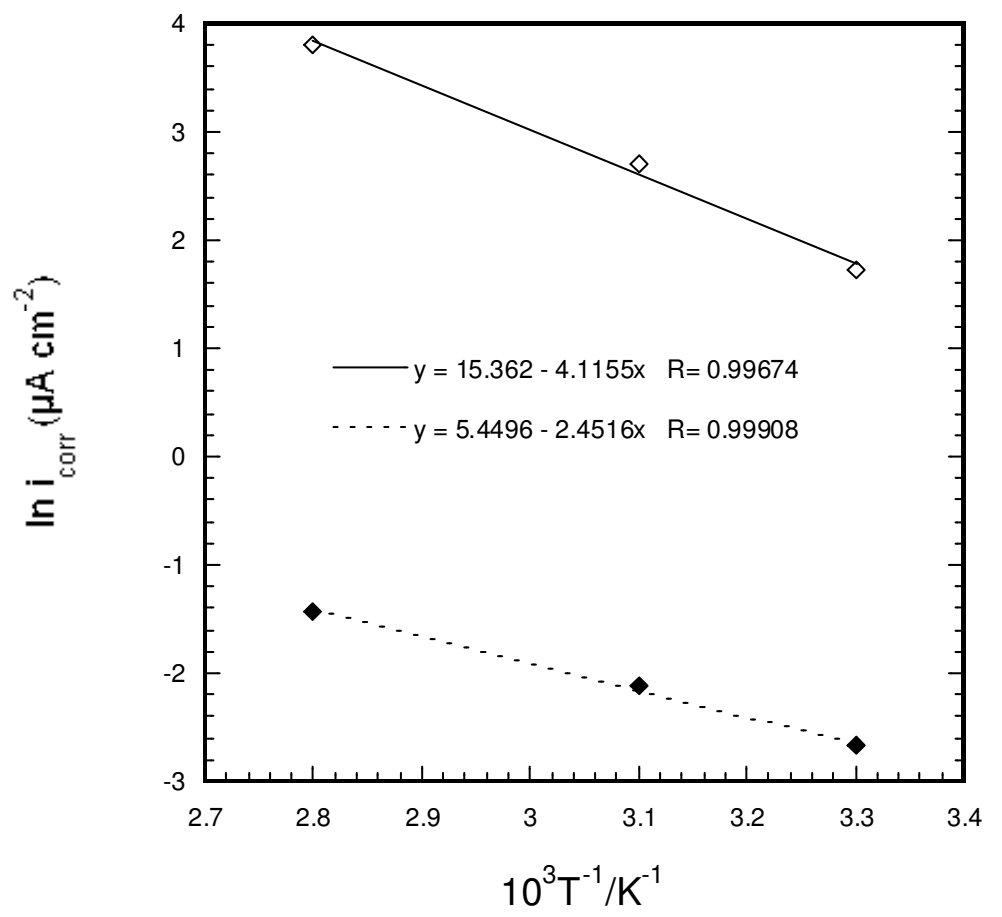

Figure 4. Arrhenius plots for uninhibited $(\diamond)$ and inhibited $(\diamond)$ mild steel in potable water.

From the Arrhenius plots above, the apparent activation energies were 34.2 $\mathrm{kJ} / \mathrm{mol}$ and $20.4 \mathrm{~kJ} / \mathrm{mol}$ for the blank and inhibited, respectively. From these results, it is evident that addition of inhibitor reduces the value of the apparent 
activation energy. This reduction of the activation energy in the presence of Acacia seyal var. seyal may be attributed to the chemisorption $[16,17]$.

\section{Conclusion}

In conclusion, Acacia gum exudates, a natural product from Acacia seyal var. seyal collected from Singida, Tanzania, was found to inhibit efficiently the corrosion of mild steel exposed in potable water. The study also shows that the inhibition efficiency was insignificantly affected by the temperature rise. Potentiodynamic polarization studies clearly reveal that the gum behaves predominantly as an anodic inhibitor.

Acknowledgment: The authors wish to thank Sida/SAREC for financial support.

\section{References}

1. A.M. Shams El din, Desalination 60 (1986) 75.

2. Guidelines for Drinking Water Quality, Vol. 1, WHO Publications, Geneva (1984).

3. P.B. Benett, W.S. Gerald, Proc. Int. Congr. Met. Corrosion 2 (1984) 291.

4. T.H.Y. Tebbut, Principles of Water Quality Control, Pergamon Oxford, (1983), p. 76.

5. E. Khamis, N. AlAndis, Mat.-wiss. u. werkstofftech 33 (2002) 550.

6. H.I. Farooqi, M.A. Quraishi, P.A. Saini, Proceedings from European Federation of Corrosion (EUROCORR. '97) (1997) p. 247.

7. D. Mukherjee, J. Berchman, A. Rajsekkar, N. Sundarsanan, R. Mahalingam, S. Maruthamuthu, T. Thiruchelvam, D. Karaikudi, Anti-Corrosion Methods and Materials 44(3) (1997) 186.

8. A.M. Abdel-Gaber, B.A. Abd-El Nabey, I.M. Sidahmed, A.M. El-Zayady, M. Saadawy, Corrosion 62(4) (2006) 293.

9. JECFA/FAO; Specifications for Identity and Purity of Certain Food Additives, Food and Nutrition, Paper No. 49, FAO, Rome (1990).

10. M. Glicksman, Ed.; Food hydrocolloids, Vol. I and II, CRC Press, Inc., Boca Raton, Florida (1983).

11. D.M.W. Anderson, J.F. Stoddart, Carbohydr. Res. 2 (1966) 104.

12. G. Trabanelli, Corrosion/89, Paper No 133 (1989).

13. O.L. Riggs, Theoretical aspects of corrosion inhibitors and inhibition in corrosion inhibitors, by C.C Nathan (Ed.) NACE (1973).

14. J.Y.N. Philip, J. Buchweishaija, and L.L. Mkayula, Tanz. J. Sci. 27 (2001) 9.

15. K. Juttner, Electrochim. Acta 35 (1990) 1501.

16. T. Szauer, A. Brand, Electrochim. Acta 26 (1981) 1219.

17. S. Sankarapapavinasam, F. Pushpanaden, M. Ahmed, Corros. Sci. 32 (1991) 193. 